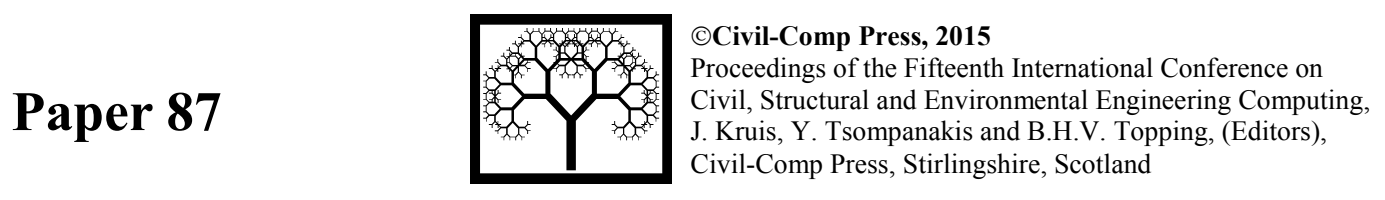

\title{
Influence of Masonry Infill Modelling on the Seismic Response of Reinforced Concrete Frames
}

\author{
L. Liberatore and F. Mollaioli \\ Department of Structural and Geotechnical Engineering \\ Sapienza University of Rome, Italy
}

\begin{abstract}
In this paper the influence of masonry infill modelling on the seismic response of reinforced concrete frames is investigated. First, various models are described and discussed, then a reinforced concrete frame, designed to be representative of an existing building in Italy, is analysed by means of numerical non linear static (pushover) analyses considering both the bare frame (as a reference model) and the infilled one. Different macro-models based on the equivalent strut approach are used with the aim of carrying out a comparison between them. The analyses are performed by means of the OpenSees software package. Beams and columns are modelled with elastic beam elements connected in series to zero-length nonlinear rotational springs located at member ends for representing plastic hinges. The infills are modelled with truss elements, to which a uniaxial material is assigned. The parameters, which characterize the uniaxial material, change with the infill model adopted. The results show that there is a noticeable difference of stiffness and strength estimated by means of different models.
\end{abstract}

Keywords: masonry infills, predicting models, equivalent strut, reinforced concrete frames, pushover analyses.

\section{Introduction}

The influence of infills on the seismic response of frame structures has long been recognised. Stiffness and strength of the infill and connections between infill and frame are usually such that the infill modifies the global seismic behaviour of the structure. Regularly distributed infills may significantly contribute to withstand the seismic actions, as also proved during moderate and strong earthquakes, reducing the deformation demand and improving the energy dissipation capacity of the system [1][2]. On the contrary, irregular arrangement of infills may be strongly 
detrimental, producing unfavourable distribution of plastic hinges, high demand of inelastic deformations, brittle failures, reduction of the global dissipation capacity.

Simple models, such as the equivalent diagonal no-tension strut model, have been developed to consider the presence of infills in the analysis and design procedures of new buildings and in the seismic assessment of existing ones. The objective of the present study is to investigate the influence of masonry infills modelling on the seismic response of reinforced concrete (RC) frame structures. First of all, a selection of strut models available in the literature is carried out. Afterward an infilled RC frame, designed in accordance with a past seismic code, is analysed by means of numerical nonlinear analyses considering both the bare frame (as a reference model) and the infilled one. In the study five infill models are used with the aim of carrying out a comparative assessment.

\section{$2 \quad$ Masonry infill modelling}

Several analytical models have been developed to represent the behaviour of infilled frames. They may be divided roughly into two groups according to whether they are based on micro- or macro-modelling approaches.

The former is based on a finite element representation of the frame and the infill. The response of the frame, the infill and their interface is described by means of proper constitutive relations. For example, smeared crack models have been often used to model both the frame and the infills; these models cannot capture different aspects, such as the shear sliding of masonry mortar. To reproduce this effect, several plasticity-based continuous interface models have been developed [3]. In general, this approach is quite complex due to the large amount of information demanded. Often, the finite element analyses of infilled frames were aimed to the calibration of the parameter for the constitutive laws of simpler models, like the equivalent strut model.

The equivalent diagonal strut model was initially based on the observation that the compressive path in the masonry panel, due to a horizontal load, develops mainly along its diagonal. Therefore, a way of representing the stiffening and strengthening effect of the masonry infill is replacing the panel with an equivalent no tension strut acting along the compressive path [4][5]. The width of the strut depends on different features, such as the extension of the region of interaction between masonry and frame. The ultimate strength of the infills depends also on the failure mechanism, which is somewhat difficult to predict being affected by many factors, such as the material properties, the dimensions of the system and the vertical stress in the panel. The strut models, even though are not able to capture the local phenomena, which take place at the infill-frame interface, are characterized by an advantageous simplicity and may also be used for perforated infills [6]. Multiple strut configurations have also been proposed with the aim of capturing the interaction between the infill panel and the frame (e.g. [7][8][9]). The multiple strut approach allows to account for the shear transmission in critical regions and for the shifting of the section of maximum bending moment but the calibration of the necessary parameters is somewhat complex. The use of this method is recommended 
for building not designed for seismic loads, having insufficient shear reinforcement and strong infills.
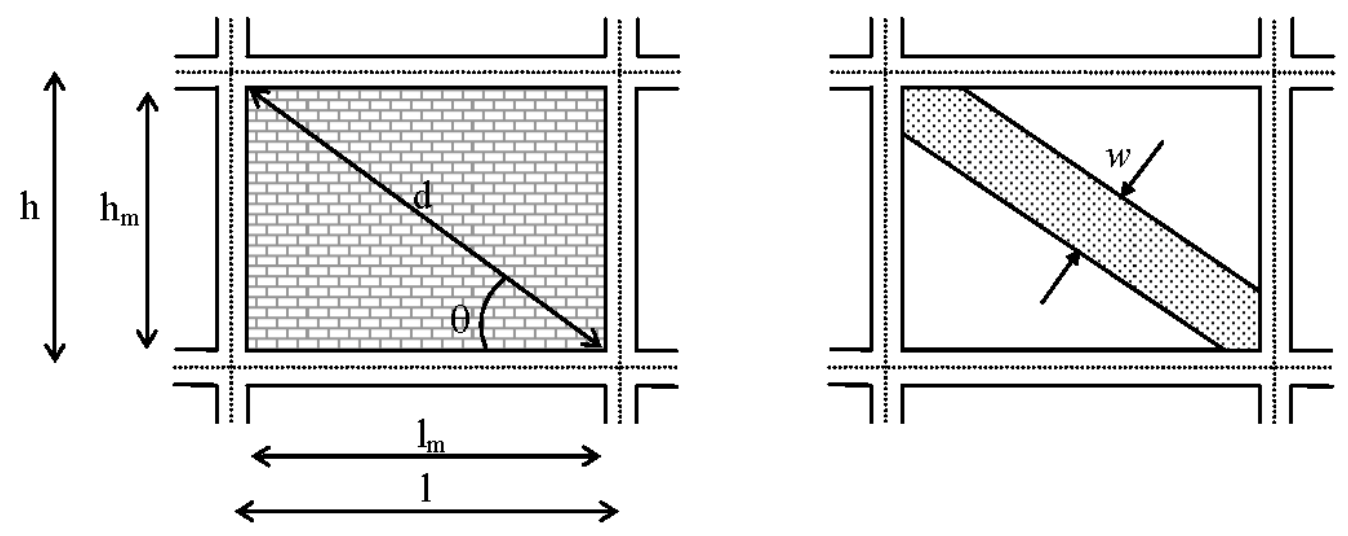

Figure 1: Equivalent strut modelling of infill.

\subsection{Equivalent strut models considered}

Different models have been proposed for the estimation of the stiffness and strength of the strut. In the following, those adopted in this study are briefly described with reference to the strength assessment ( $\S 2.2 .1)$, to the equivalent width estimation ( $\S$ 2.2.2) and to the modelling of the constitutive law (§2.2.3).

\subsubsection{Strength of the equivalent diagonal strut}

As observed by Haldar et al. [10] on the basis of a thorough investigation of the research of the last five decades, four distinct failure modes of the infill panel have been identified: i) bed-joint sliding shear failure; ii) cracking due to diagonal tension; iii) diagonal compression failure and iv) corner crushing of the infill.

The models considered here take into account different failure modes, as indicated in Table 1. These models have shown a good agreement with different experimental results and are advantageous for their simplicity.

\begin{tabular}{lcccc}
\hline Reference & $(1)$ & $(2)$ & $(3)$ & $(4)$ \\
\hline Liauw and Kwan [11] & no & no & yes & yes \\
Decanini and Fantin [12] & yes & yes & yes & yes \\
Paulay and Priestley [13] & yes & yes & yes & no \\
Priestley and Calvi [14] & & & & \\
Saneinejad and Hobbs [15] & yes & yes & yes & yes \\
FEMA 306 [16] & yes & yes & no & yes \\
\hline
\end{tabular}

(1) Failure due to bed-joint sliding; (2) Cracking due to diagonal tension; (3) Failure due to diagonal compression; (4) Failure due to corner crushing

Table 1: Failure modes taken into account in the considered models. 
In the plastic collapse theory developed by Liauw and Kwan [11] the failure mode depends on panel proportions and relative strengths of the columns, beams and infill. Three modes of failure are identified: i) diagonal crushing (Equation 1); ii) corner crushing with failure in columns (Equation 2) and iii) corner crushing with failure in beams (Equation 3).

$$
\begin{gathered}
R_{d c}=\left(\frac{4 M_{p j}}{h}+\frac{f_{m}^{\prime} t h}{6}\right) \frac{1}{\cos \theta} \quad l>h \\
R_{d c}=\left(\frac{4 M_{p j}}{h}+\frac{f_{m}^{\prime} t h}{6 \tan ^{2} \theta}\right) \frac{1}{\cos \theta} \quad l<h \\
R_{c c 1}=\frac{\sqrt{2\left(M_{p j}+M_{p c}\right) f_{m}^{\prime} t}}{\cos \theta} \\
R_{c c 2}=\frac{\sqrt{2\left(M_{p j}+M_{p b}\right) f_{m}^{\prime} t}}{\operatorname{sen} \theta}
\end{gathered}
$$

where $R_{d c}$ is the strength of the strut in the diagonal crushing failure mode; $R_{c c 1}$ and $R_{c c 2}$ are the corner crushing strengths of the strut with failure in columns and in beams, respectively; $t$ is the panel thickness; $h, l$ and $\theta$ are depicted in Figure $1 ; f_{m}^{\prime}$ is the masonry compressive strength; $M_{p b}$ and $M_{p c}$ are the plastic moments of beam and column, respectively; $M_{p j}$ is the plastic moment of joint, i.e. the smaller value between $M_{p b}$ and $M_{p c}$.

In the model by Decanini and Fantin [12] the axial strength of the strut in different failure modes is expressed as:

$$
\begin{gathered}
R_{s}=\left[(1.2 \operatorname{sen} \theta+0.45 \cos \theta) \tau_{0}+0.3 \sigma_{y}\right] t d \\
R_{d t}=\left(0.6 \tau_{m 0}+0.3 \sigma_{y}\right) t d \\
R_{d c}=\frac{1.16 \tan \theta}{k_{1}+k_{2} \lambda_{h}} f_{m}^{\prime} t w \\
R_{c c}=\frac{1.12 \operatorname{sen} \theta \cos \theta}{k_{1} \lambda_{h}^{-0.12}+k_{2} \lambda_{h}^{0.88}} f_{m}^{\prime} t w
\end{gathered}
$$


where $R_{S}$ is the strength in the bed-joint sliding failure mode; $R_{d t}$ is the strength in the diagonal tension failure mode; $R_{d c}$ is the strength in the diagonal compression failure mode and $R_{c c}$ is the strength in the corner compression failure mode. Moreover, $d$ is the length of the strut; $\tau_{0}$ is the basic shear strength of bed joints; $\tau_{m 0}$ is the shear strength evaluated through diagonal compression tests; $\sigma_{y}$ is the vertical stress; $w$ is the width of the equivalent strut (see Table 2 ); $\lambda_{h}$ is a non-dimensional parameter (Equation 19) and values of $k_{1}$ and $k_{2}$ are reported in Table 2.

According to Paulay and Priestley [13] the strut force to initiate sliding in infill panels depends on the shear friction stress and on the aspect ratio of the panel:

$$
\begin{gathered}
R_{s}=\frac{\tau_{0}}{1-\mu(h / l)} t d \\
\tau_{0}=0.03 f_{m}^{\prime} \quad \mu=0.3
\end{gathered}
$$

where $\mu$ is the coefficient of friction.

The diagonal compression strength is function of vertical contact length, $z$, between infill and column:

$$
\begin{gathered}
R_{d c}=\frac{2}{3} z t f_{m}^{\prime} \sec \theta \\
z=\frac{\pi}{2} \frac{h}{\lambda_{h}}
\end{gathered}
$$

In Priestley and Calvi [14] the diagonal tension cracking failure is also considered. This failure mode does not produce itself the infill collapse, however the in-plane damage due to cracking contributes to the out-of-plane expulsion of the panel. The diagonal force, which induces diagonal tension cracking, is evaluated using the relationship for tensile stress in a disk loaded along a diameter:

$$
R_{t}=\frac{\pi}{2} t d f_{m}^{\prime}
$$

In the analytical method developed by Saneinejad and Hobbs [15] all failure modes are considered. The strength of the strut in the shear failure mode due to a complete horizontal crack through bed joints is:

$$
R_{s}=\min \left\{\begin{array}{c}
\frac{\gamma \tau_{0} t d}{1-0.45 \tan \theta^{\prime}} \\
0.83 \gamma t d
\end{array}\right.
$$

where $\gamma$ is the load factor and $\theta^{\prime}$ is depicted in Figure 2. 
Diagonal cracking of the infill is regarded as a serviceability limit state, however, as observed in [14] it may be related to a collapse limit state because presence of diagonal cracking in both diagonals accelerates the out-of-plane failure of the infill. For the cracking load the following equation is suggested:

$$
R_{d t}=2 \sqrt{2} t h_{m} f_{t}^{\prime} \cos \theta
$$

where $f_{t}^{\prime}$ is the tensile strength of infill material.

According to [15] the collapse is related to the shear failure, however corner crushing and diagonal compression failure modes are assessed to estimate the cross section area of the strut. The diagonal compression strengths is given by the following equation:

$$
\begin{gathered}
R_{d c}=\frac{0.5 h_{m} t f_{a}}{\cos \theta} \\
f_{a}=0.39 f_{m}^{\prime}\left[1-\left(\frac{l_{\text {eff }}}{40 t}\right)^{2}\right]
\end{gathered}
$$

where $f_{a}$ is the permissible stress, which takes into account the out-of-plane buckling and $l_{e f f}$ is the effective length of the strut (Figure 2). From the above formula it results that the permissible stress is negative when the thickness of the infill is smaller than $2.5 \%$ of the effective length.

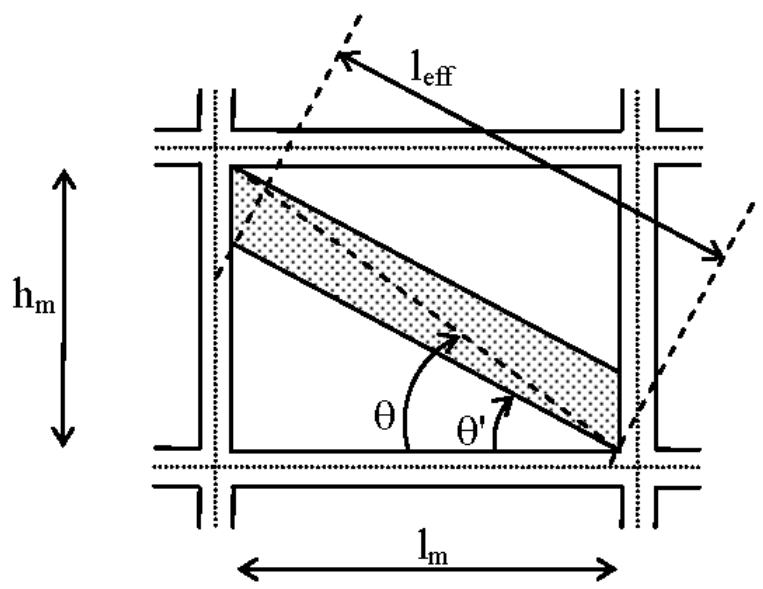

Figure 2: Definition of $\theta^{\prime}$ and $l_{e f f}$ in the Saneinejad and Hobbs model [15].

Finally, the corner crushing strength according to [15] is:

$$
R_{c c}=\frac{\left(1-\alpha_{c}\right) \alpha_{c} h t \sigma_{c}+\alpha_{b} l t \tau_{b}}{\cos \theta}
$$


where: $\alpha_{c} h$ and $\alpha_{b} l$ are the contact lengths between infill and columns and infill and beam and $\sigma_{c}$ and $\tau_{b}$ are the column-infill and beam-infill contact stresses, respectively.

Three potential in-plane failure modes are considered in FEMA 306 [16]. The Mohr-Coulomb failure criteria is used to assess the sliding-shear capacity of the infill, the corresponding strut resistance may be calculated as:

$$
R_{s}=\frac{\left(\tau_{0}+\mu \sigma_{y}\right) l t}{\cos \theta}
$$

where $\tau_{0}$ may be taken as $1 / 40$ times the compressive strength of masonry, $\mu$ is the coefficient of sliding friction along the bed joints and $\sigma_{y}$ is the vertical stress.

The diagonal tension strength in [16] is the same as suggested by Saneinejad and Hobbs (Equation 12). The cracking strength of masonry may be taken as $1 / 20$ of the compressive strength estimated in the horizontal direction, $f_{m 90}^{\prime}$.

For corner compression failure a modified version of the method proposed by Stafford-Smith and Carter [17] is suggested:

$$
R_{c}=w t f_{m 90}^{\prime}
$$

where $f_{m 90}^{\prime}$ may be taken as one half of the stacked prism strength.

\subsubsection{Width of the equivalent diagonal strut}

The axial stiffness of the strut, $k_{m}$, may be estimated as:

$$
k_{m}=\frac{E_{m} t w}{d}
$$

where $E_{m}$ is the modulus of elasticity of masonry, $t$ is the panel thickness, $w$ is the width of the strut and $d$ is its length. The equations used to estimate $w$ are reported in Table 2.

The parameter $\lambda_{h}$ in the expressions by Liauw and Kwan [11], Decanini and Fantin [12] and FEMA 306 [16] is a non-dimensional parameter introduced by Stafford-Smith [4] to take into account the influence of the relative stiffness of the frame and the infill:

$$
\lambda_{h}=\sqrt[4]{\frac{E_{m} t \operatorname{sen} 2 \theta}{4 E I h_{m}}} h
$$

where: $E_{m}$ and $E$ are the modulus of elasticity of the masonry and of the frame, respectively and $I$ is the moment of inertia of columns (see $\S 2.2 .1$ for definitions of other parameters). 


\begin{tabular}{|c|c|c|}
\hline Reference & \multicolumn{2}{|c|}{ Equivalent width } \\
\hline Liauw and Kwan [18] & $w=\frac{0.95 h_{m} c o}{\sqrt{\lambda_{h}}}$ & $25^{\circ}<\theta<50^{\circ}$ \\
\hline \multirow{3}{*}{ Decanini and Fantin [12] } & \multirow{3}{*}{$w=\left(\frac{k_{1}}{\lambda_{h}}+k_{2}\right)$} & $\begin{array}{c}\text { for } \lambda_{h}<3.14 \\
k_{1}=1.3 \quad k_{2}=-0.178\end{array}$ \\
\hline & & $\begin{array}{c}\text { for } \quad 3.14<\lambda_{h}<7.85 \\
k_{1}=0.707 \quad k_{2}=0.01\end{array}$ \\
\hline & & $\begin{array}{c}\text { for } 7.85<\lambda_{h} \\
k_{1}=0.47 \quad k_{2}=0.04\end{array}$ \\
\hline $\begin{array}{l}\text { Paulay and Priestley [13] } \\
\text { Priestley and Calvi [14] }\end{array}$ & \multicolumn{2}{|c|}{$w=\frac{d}{4}$} \\
\hline Saneinejad and Hobbs [15] & \multicolumn{2}{|c|}{$\begin{array}{c}\frac{\left(1-\alpha_{c}\right) \alpha_{c} h \frac{\sigma_{c}}{f_{c}}+\alpha_{b} l \frac{\tau_{b}}{f_{c}}}{\cos \theta} \\
0.5 \frac{h_{m} \frac{f_{a}}{f_{c}}}{\cos \theta}\end{array}$} \\
\hline FEMA 306 [16] & $w=$ & $\left(\lambda_{h}\right)^{-0.4} d$ \\
\hline
\end{tabular}

Table 2: Equations used for the equivalent width calculation.

The empirical equation by Liauw and Kwan is based on experimental data on steel frames. The equation suggested by Paulay and Priestley, which gives a conservative value of the width, is recommended for a lateral force level of $50 \%$ of the ultimate capacity. The expression by Decanini and Fantin, which provides the secant stiffness of the strut, is calibrated through experimental data on reinforced concrete frames.

The value suggested by Saneinejad and Hobbs is related to the attainment of the resisting loads $R_{c c}$ and $R_{d c}$ (compare equations in Table 2 with Equations 15 and 13). For the calculation of the secant modulus of elasticity they introduced the following equation:

$$
\begin{gathered}
E_{d}=\frac{h f_{c}}{\Delta_{\mathrm{h}} \cos ^{2} \theta} \\
\Delta_{\mathrm{h}}=5.8 \varepsilon_{c} h \cos \theta\left(\alpha_{c}^{2}+\alpha_{b}^{2}\right)^{0.333}
\end{gathered}
$$

where $\Delta_{\mathrm{h}}$ is the horizontal infill deflection and $\varepsilon_{\mathrm{c}}$ is the infill strain at peak uniaxial compression. The other symbols are defined in $\S 2.2 .1$. 


\subsubsection{Constitutive and cyclic law of the equivalent diagonal strut}

The use of the equivalent strut to perform nonlinear push-over and time history analyses requires the definition of adequate constitutive and cyclic models. Different laws have been proposed, usually based on comparisons with observed results of experimental tests. The constitutive law may be defined by a multi-linear relationship [19][20], or by a combination of linear and non-linear brunches [21], or by smoothed curves [8]. Details on these models are provided in [22][23].

In this study, the multi-linear model shown in Figure 3 is used [20]. The main parameters necessary to define the constitutive curve are the elastic stiffness, $k_{0}$, the secant stiffness, $k_{m}$, and the strength of the strut, $R_{m}$. The strength is evaluated according to different models as reported in $\S 2.2 .1$. For each model considered, the strength $R_{m}$ is the minimum among different failure modes. The secant stiffness is evaluated through Equation 18, the strut width is estimated by means of the equations reported in Table 2. The elastic stiffness is estimated under the hypothesis that the ratio between the elastic stiffness and the secant stiffness of the infilled frame is equal to 4 and that the infill yields when the frame is in the elastic range [24].

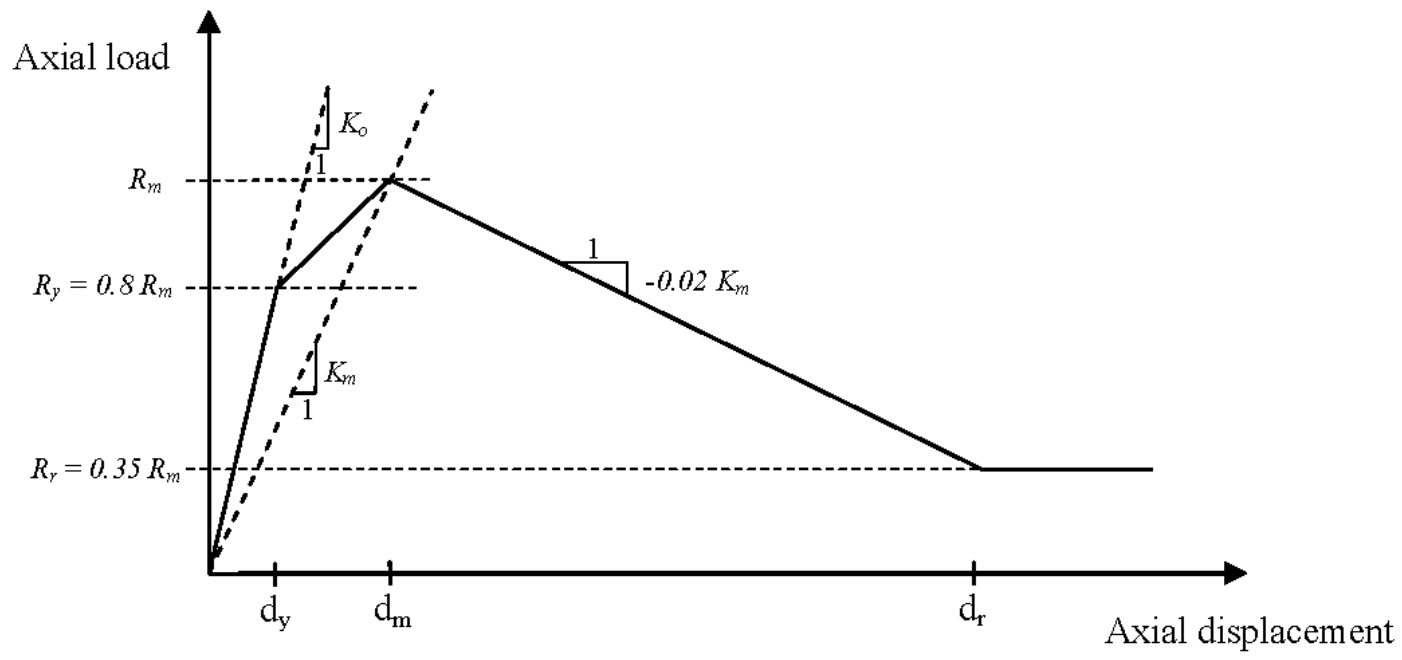

Figure 3: Constitutive law of the strut [20].

The cyclic behaviour of an infill is generally characterized by the degradation of stiffness in the unloading brunch, the degradation of strength under displacement cycles of constant amplitude and the pinching due to cracks developed in the previous cycles. Different models are discussed in [22]. Since the effect of infills is investigated here by means of push-over analyses, the modelling of the hysteretic behaviour is disregarded. 


\section{Case study}

\subsection{Description and Modelling with OpenSees}

Six-storey, three-bay bare and infilled reinforced concrete frames are examined. Span length and storey height are equal to $6.0 \mathrm{~m}$ and $3.5 \mathrm{~m}$, respectively. The frame elements are dimensioned to be representative of an existing structure designed according to a past seismic code in a high seismic zone in Italy. Capacity design and local ductility criteria, prescribed by many current codes, have not been applied. The presence of infills is neglected in the design, i.e. size and reinforcement of beams and columns are the same for the bare and the infilled frames. Concrete with cylindrical compressive strength of $25 \mathrm{MPa}$ and steel with a yield strength of 440 MPa are used.

A masonry representative, in terms of strength and stiffness, of those used in Italy and in other South-European countries is used for the infills. The geometrical and mechanical characteristics are reported in Table 3. The infills are distributed uniformly throughout the building.

\begin{tabular}{ccccccccc}
\hline $\begin{array}{c}l_{m} \\
(\mathrm{~m})\end{array}$ & $\begin{array}{c}h_{m} \\
(\mathrm{~m})\end{array}$ & $\begin{array}{c}t \\
(\mathrm{~m})\end{array}$ & $\begin{array}{c}f_{m}^{\prime} \\
(\mathrm{MPa})\end{array}$ & $\begin{array}{c}E_{m} \\
(\mathrm{MPa})\end{array}$ & $\begin{array}{c}\tau_{m 0} \\
(\mathrm{MPa})\end{array}$ & $\begin{array}{c}\tau_{0} \\
(\mathrm{MPa})\end{array}$ & $\begin{array}{c}f_{t}^{\prime} \\
(\mathrm{MPa})\end{array}$ & $\mu$ \\
\hline 5.55 & 2.90 & 0.145 & 2.20 & 2.40 & 0.44 & 0.39 & 0.22 & 0.3 \\
\hline$l_{m}=$ length; & $h_{m}=$ height; $\mathrm{t}=$ thickness; $f_{m}^{\prime}=$ compressive strength; $E_{m}=$ elastic modulus; $\tau_{m 0}=$ shear \\
strength estimated through a diagonal compression test; & $\tau_{0}=$ basic shear strength of bed joints; $f_{t}^{\prime}=$ \\
tensile strength; $\mu=$ coefficient of sliding friction along bed joints.
\end{tabular}

Table 3: Properties of masonry infill.

The frame model is built in OpenSees [25]. Beams and columns are modelled with elastic beam elements connected in series to zero-length nonlinear rotational springs located at member ends for representing plastic hinges. The value of the axial load used in the evaluation of the moment-chord rotation constitutive law is zero for the case of the beams, and equal to the gravity load for the case of the columns. The infills are modelled with truss elements, to which a multi-linear hysteretic uniaxial material is assigned. The parameters, which characterize the uniaxial material, vary with the model adopted.

\subsection{Results and discussion}

The variation of strength and width of the strut with varying infill aspect ratio $\left(h_{m} / l_{m}\right)$ is shown in Figure 4 and Figure 5, respectively. Aspect ratios greater than one are not usual, however they are reported here to show the general trends. In the case investigated the aspect ratio is equal to 0.52 , the corresponding values of strength and width are reported in Table 4. The Saneinejad and Hobbs model provides negative values of the diagonal compression strength $R_{d c}$ (Equation 13) 
and of the equivalent width. This is due to the use of the permissible stress $f_{a}$ (Equation 14) instead of the compressive strength $f_{m}^{\prime}$ used in the other models. In the case study $f_{a}$ is negative because the thickness of the masonry panel is less than $2.5 \%$ of the effective length of the strut. The model proposed by Saneinejad and Hobbs is therefore not applicable to the case under investigation and has been disregarded in the analysis of the multi-storey frame.

The stiffness of the strut varies with the model considered. The equivalent width ranges between $11.5 \%$ and $28 \%$ of the strut length. Concerning the failure mode, there is no agreement among various models: according to Liauw and Kwan [11] failure is due to diagonal compression; according to Decanini and Fantin [12] diagonal tension occurs first; a sliding failure mode is obtained by applying the equations in [13][14] and a corner compression failure is obtained using the FEMA 306 recommendations [16]. In the model by Saneinejad and Hobbs [15], excluding the diagonal compression failure mode, the corner compression failure mode provides the minimum value of the strength.
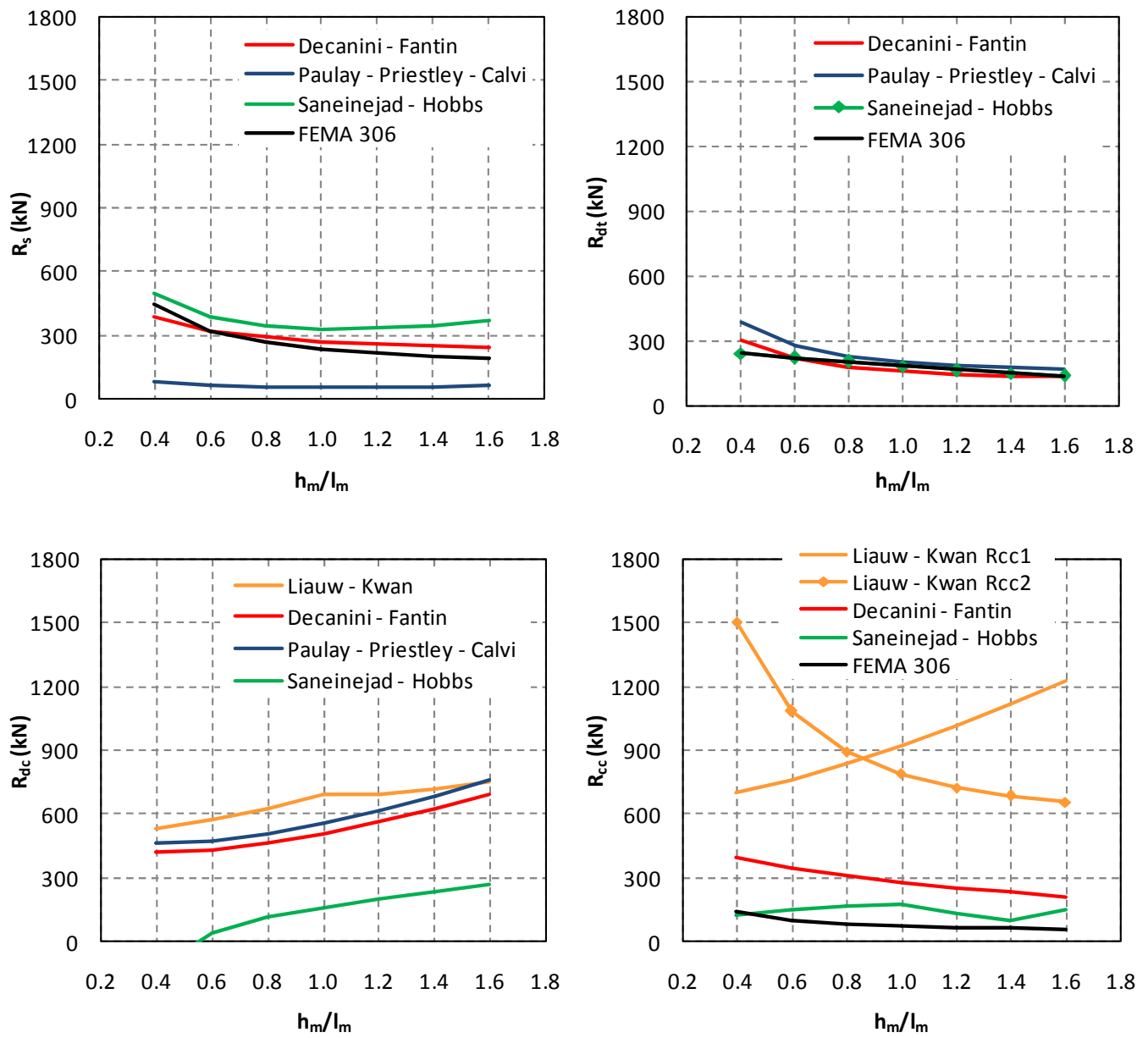

Figure 4: Infill strength in different failure modes. 


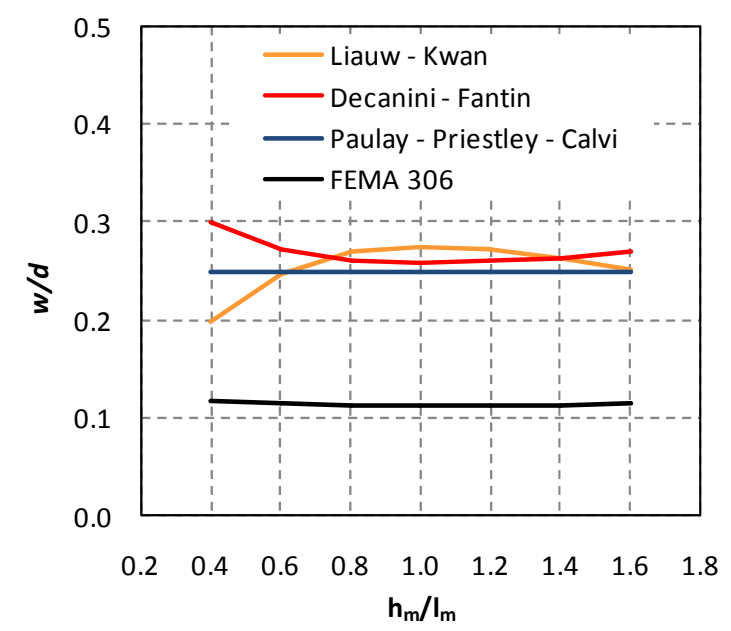

Figure 5: Equivalent width of the strut divided by the strut length.

\begin{tabular}{|c|c|c|c|c|c|}
\hline Reference & $w / d$ & $R_{S}(\mathrm{kN})$ & $R_{d t}(\mathrm{kN})$ & $R_{d c}(\mathrm{kN})$ & $R_{c c}(\mathrm{kN})$ \\
\hline $\begin{array}{l}\text { Liauw and Kwan [11][18] } \\
\text { Storey } 1,2,3^{*}\end{array}$ & 0.232 & - & - & 555 & $\begin{array}{l}R_{c c 1}=735 \\
R_{c c 2}= \\
1206\end{array}$ \\
\hline $\begin{array}{l}\text { Liauw and Kwan [11] [18] } \\
\text { Storey } 4,5,6^{*}\end{array}$ & 0.232 & - & - & 430 & $\begin{array}{l}R_{c c 1}=593 \\
R_{c c 2}=989\end{array}$ \\
\hline Decanini and Fantin [12] & 0.280 & 343 & 245 & 427 & 367 \\
\hline $\begin{array}{l}\text { Paulay and Priestley [13] } \\
\text { Priestley and Calvi [14] }\end{array}$ & 0.250 & 73 & 314 & 465 & - \\
\hline $\begin{array}{l}\text { Saneinejad and Hobbs } \\
{[15]} \\
\text { Storey } 1,2,3^{*}\end{array}$ & $<0$ & 420 & 232 & $<0$ & 143 \\
\hline $\begin{array}{l}\text { Saneinejad and Hobbs } \\
\text { [15] } \\
\text { Storey } 4,5,6^{*}\end{array}$ & $<0$ & 420 & 232 & $<0$ & 140 \\
\hline FEMA 306 [16] & 0.115 & 359 & 232 & - & 115 \\
\hline \multicolumn{6}{|c|}{$\begin{array}{l}\text { w/d }=\text { equivalent width/length of the diagonal strut; } R_{s}=\text { strength in the bed-joint sliding failure } \\
\text { mode; } R_{d t}=\text { strength in the diagonal tension failure mode; } R_{d c}=\text { strength in the diagonal } \\
\text { compression failure mode; } R_{c c}=\text { strength in the corner compression failure mode. } \\
\text { *In the Liauw and Kwan and Saneinejad and Hobbs formulations, values depend on the plastic } \\
\text { moments of frame elements, therefore different values are obtained at different storeys. }\end{array}$} \\
\hline
\end{tabular}

Table 4: Equivalent width and strength of the infill according different models.

The push-over curves of the six-storey frame are depicted in Figure 6, where $\mid \mathrm{V}_{\text {base }} / \mathrm{W}$ is the base shear normalised by the building weight and RDR is the roof drift ratio, i.e the roof horizontal displacement divided by the building height. In Table 5 there are reported: the maximum base shear, $V_{\max }$; the yielding displacement, $u_{y}$; the displacement at $V_{\max }, u_{V \max }$; the ratio between the first period of 
vibration of the infilled frame and that of the bare frame, $T_{\text {inf }} / T_{\text {bare }}$; the ratio between the secant stiffness of the infilled frame and that of the bare frame, $K_{\text {inf }} / K_{\text {bare }}$ and the ratio between the strength of the infilled frame and that of the bare frame, $V_{\text {max,inf }} / V_{\text {max,bare }}$. Both the yielding displacement and the secant stiffness are estimated considering an equivalent bi-linear curve with a constant branch at $V_{\max }$ and the total energy dissipated at $u_{V \max }$ equal to that of the actual pushover curve.

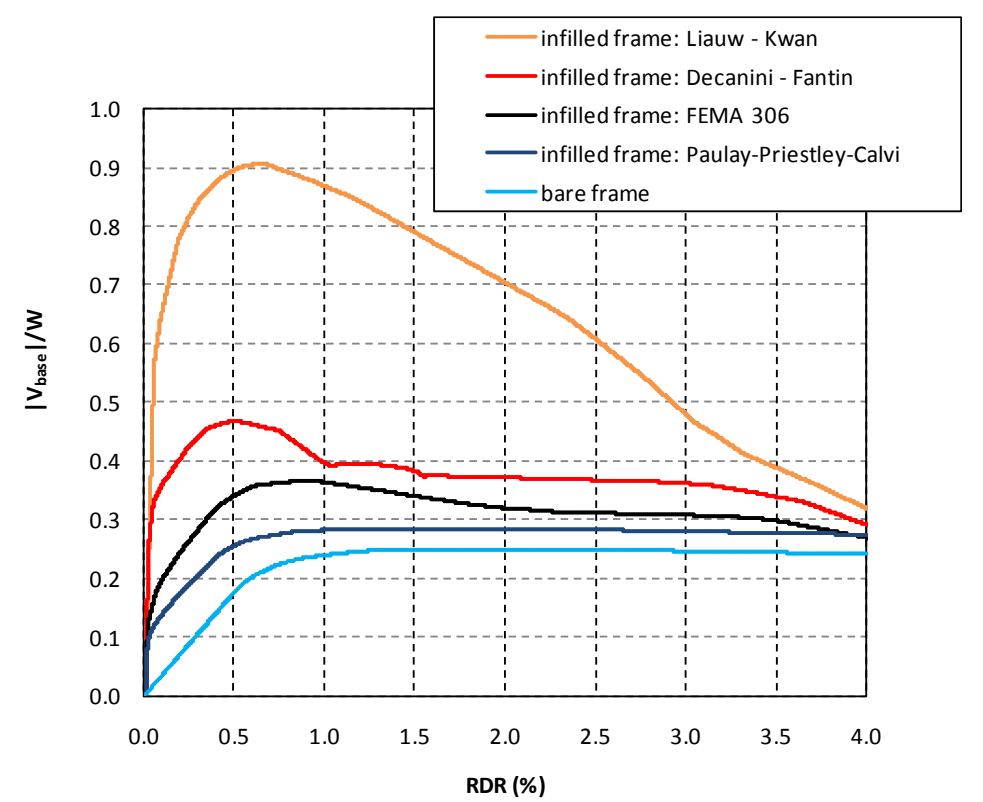

Figure 6: Push-over curves of bare and infilled frames.

\begin{tabular}{|c|c|c|c|c|c|}
\hline & $\begin{array}{l}\text { Bare } \\
\text { frame }\end{array}$ & $\begin{array}{c}\text { Infilled } \\
\text { Liauw and } \\
\text { Kwan [11] }\end{array}$ & $\begin{array}{c}\text { Infilled } \\
\text { Decanini } \\
\text { and Fantin } \\
{[12]}\end{array}$ & $\begin{array}{c}\text { Infilled Paulay } \\
\text { and Priestley } \\
\text { [13] Priestley } \\
\text { and Calvi [14] }\end{array}$ & $\begin{array}{c}\text { Infilled } \\
\text { FEMA } 306 \\
{[16]}\end{array}$ \\
\hline$V_{\max }(\mathrm{kN})$ & 536 & 1951 & 1006 & 613 & 789 \\
\hline$u_{y}(\mathrm{~m})$ & 0.163 & 0.039 & 0.031 & 0.083 & 0.069 \\
\hline$u_{\operatorname{Vmax}}(\mathrm{m})$ & 0.354 & 0.133 & 0.104 & 0.248 & 0.188 \\
\hline$T_{\text {inf }} / T_{\text {bare }}$ & - & 0.173 & 0.150 & 0.166 & 0.196 \\
\hline$K_{\text {inf }} / K_{\text {bare }}$ & - & 15.3 & 9.98 & 2.25 & 3.47 \\
\hline $\begin{array}{l}V_{\text {max }, \text { inf }} \\
V_{\text {max }} \text { bare } \\
\end{array}$ & - & 3.64 & 1.87 & 1.14 & 1.47 \\
\hline
\end{tabular}

Table 5: Comparison between bare and infilled frames.

The period of vibration of the infilled frames according to different models is between $15 \%$ and $19.6 \%$ of the bare frame period, indicating a strong influence of 
infills on the elastic stiffness. Both the stiffness and the strength are significantly affected by the model adopted (Table 5). The ratio between the secant stiffness of the infilled frames and that of the bare frame varies noticeably with the model, ranging between 2.25 and 15.3. Concerning the strength $\left(V_{\max }\right)$, The model by Paulay and Priestley [13] and Priestley and Calvi [14] gives conservative results with respect to the other models, whereas, as expected, the adoption of the Liauw and Kwan [11] model gives the greater increment of the strength (about 3.6 times that of the bare frame). Intermediate values are obtained with the models by Decanini and Fantin [12] and FEMA 306 [16]. In general, independently by the model adopted, the effect of the infills on the stiffness is greater than that on the strength.

\section{Conclusions}

Different macro-models based on the equivalent diagonal strut approach have been used to estimate the effect of masonry infills on stiffness and strength of a six-storey $\mathrm{RC}$ infilled frame. The frame is representative of structures designed with a past seismic code. The masonry used for infill panel is typical, in terms of mechanical characteristics, of those adopted in Italy and other Mediterranean countries. Pushover analyses have been performed to assess the non-linear static behaviour of the structure.

The models considered here for the masonry infill take into account at least two of the most common failure modes, i.e. bed-joint sliding shear, cracking due to diagonal tension, diagonal compression and corner crushing of the infill. Of course, at each failure mode corresponds a different value of the strength, the minimum of which corresponds to the estimated capacity of the infill. Among the various models initially considered in the study, that of Saneinejad and Hobbs [15] has been disregarded in the analyses of the multi-storey frame because the panel thickness is such that, according to this model, an out-of-plane buckling occurs.

For the infill masonry considered, there is no agreement among various models about the failure mechanism, for example according to Decanini and Fantin [12] the failure should occur due to diagonal tension whereas a corner compression failure is attained using the FEMA 306 recommendations [16].

Concerning the equivalent width of the strut, which is directly related to its stiffness, the value estimated according to FEMA 306 [16], that is equal to $11.5 \%$ of the strut length, is smaller than the values obtained by the application of the other models, which provide values ranging between $23 \%$ and $28 \%$ of the strut length.

The influence of the infill modelling on stiffness and strength of the RC frame is noticeable: the secant stiffness of the infilled frame varies between 2.25 and 15.3 times that of the bare frame, the strength of the infilled frame varies between 1.14 and 3.64 times the bare frame strength. The model proposed by Paulay and Priestley [13] and Priestley and Calvi [14] is conservative with respect to the other models. The Liauw and Kwan model [11][18] gives the strongest and stiffest strut and seems non suitable for the masonry considered in this study. This is due to the fact that such a model does not account for the bed-joint sliding shear failure and for the 
diagonal tension failure modes. The models by Decanini and Fantin [12] and FEMA 306 [16] gives intermediate results.

On the basis of the previous results, it can be concluded that the issue of modelling infill walls seems to be still an open one. The highly variability of the material and the large number of parameters involved, makes the reliability of the modelling very hard to obtain. Anyway, the significant contribution of infill walls in the behaviour of infilled frames needs the continuation of research in this area to be an imperative issue. Finally, although some initial conclusions have been drawn from this study, more research needs to be conducted on this subject, as the interaction between infills and frame is a very problematical topic and there are several factors, including the modelling of the hysteretic behaviour, that need to be taken into account.

\section{Acknowledgements}

The financial support of the Ministry of the Instruction, University and Research of Italy (MIUR) is gratefully acknowledged. This work has been partially carried out under the program "Dipartimento di Protezione Civile - Consorzio RELUIS", signed on 2013-12-27, Research Lines WP3 and WWP5. The authors are grateful to Dr. Andrea Lucchini for his valuable help in the Opensees analyses.

\section{References}

[1] L.D. Decanini, A. De Sortis, L. Liberatore, F. Mollaioli, "Estimation of nearsource ground motion and seismic behaviour of RC framed structures damaged by the 1999 Athens earthquake”, Journal of Earthquake Engineering, 9(5), 609-635, 2005.

[2] L.D. Decanini, L. Liberatore, F. Mollaioli, "Damage potential of the 2009 L'Aquila, Italy, earthquake", Journal of Earthquake and Tsunami, 6(3), 1250032:1-32, 2012.

[3] P.B. Shing, A.B. Mehrabi, "Behaviour and analysis of masonry-infilled frames", Progress in Structural Engineering and Materials, 4(3), 320-331. 2002.

[4] B. Stafford Smith, "Lateral stiffness of infilled frames", Journal of Structural Division, ASCE, 88, no. ST6, 183-199, 1962.

[5] R.J. Mainstone, "Supplementary note on the stiffness and strength of infilled frames", Current Paper CP13/74, Build. Res. Establishment, London, England, 1974.

[6] L.D. Decanini, L. Liberatore, F. Mollaioli, "Strength and stiffness reduction factors for infilled frames with openings", Earthquake Engineering and Engineering Vibration, 13(3), 437-454, 2014.

[7] V. Thiruvengadam, "On the natural frequencies of infilled frames", Earthquake Engineering and Structural Dynamics, 31(2), 44-46, 1985. 
[8] F.J. Crisafulli, "Seismic behaviour of reinforced concrete structures with masonry infills", PhD Thesis, University of Canterbury, Christchurch, New Zealand, 1997.

[9] C.Z. Chrysostomou, P. Gergely, J.F. Abel, "A six-strut model for nonlinear dynamic analysis of steel infilled frames", International Journal of Structural Stability and Dynamics, 2(3), 335-353, 2002.

[10] P. Haldar, Y. Singh, D.K. Paul, Identification of seismic failure modes of URM infilled RC frame buildings, Engineering Failure Analysis, 33, (2013) 97-118, 2013.

[11] T.C. Liauw, K.H. Kwan, "Unified plastic analysis for infilled frames”, Journal of Structural Engineering, ASCE, 111(7), 1427-1448, 1985.

[12] L.D. Decanini, G.E. Fantin, "Modelos simplificados de la mampostería incluida en porticos. Características de rigidez y resistencia lateral en estado límite", Jornadas Argentinas de Ingenierìa Estructural, 817-836, 1987 (in Spanish).

[13] T. Paulay, M.J.N. Priestley, Seismic design of reinforced concrete and masonry buildings, John Wiley \& Sons, Inc., 1992.

[14] M.J.N. Priestley, M. Calvi, "Towards a capacity-design assessment procedure for reinforced concrete frames", Earthquake Spectra, 7(3), 413-437, 1991.

[15] A. Saneinejad, B. Hobbs, "Inelastic design of infilled frames", Journal of Structural Engineering, ASCE, 121(4), 634-50, 1995.

[16] FEMA 306, Evaluation of earthquake damaged concrete and masonry wall buildings - basic procedures manual, prepared by The Applied Technology Council, 1998.

[17] B. Stafford-Smith, C. Carter, "A method of analysis for infilled frames", Proceedings of the Institute of Civil Engineers, 44, 31-48, 1969.

[18] T.C. Liauw, K.H. Kwan, "Nonlinear behaviour of non-integral infilled frames", Computers \& Structures, 18(3), 551-560, 1984.

[19] T.B. Panagiotakos, M.N. Fardis, "Seismic response of infilled RC frames structures", XXI World Conference on Earthquake Engineering, Acapulco, paper n. 225, 1996.

[20] L. Liberatore, Approcci innovativi in termini di energia e spostamento per la valutazione della risposta sismica di strutture a più gradi di libertà. $\mathrm{PhD}$ Thesis, University of Rome La Sapienza, Italy, 2001 (in Italian).

[21] R.E. Klingner, V.V. Bertero, "Earthquake resistance of infilled frames", Journal of Structural Division, ASCE, 104(6), 973-989, 1978.

[22] F. Di Trapani, G. Macaluso, L. Cavaleri, M. Papia, "Masonry infills and RC frames interaction: literature overview and state of the art of macromodeling approach", European Journal of Environmental and Civil Engineering, DOI:10.1080/19648189.2014.996671, 2015.

[23] N. Tarque, L. Candido, G. Camata, E. Spacone, "Masonry infilled frame structures: state-of-the-art review of numerical modelling", Earthquakes and Structures, 8(3), 733-759, 2015.

[24] L. Liberatore, L.D. Decanini, "Effect of infills on the seismic response of high-rise RC buildings designed as bare according to Eurocode 8", Ingegneria Sismica, 3, 3-23, 2011. 
[25] F. McKenna, G.L. Fenves, M.H. Scott, OpenSees: Open System for Earthquake Engineering Simulation, Version 2.4.4. PEER, University of California, Berkeley, CA. Available from: http://opensees.berkeley.edu [accessed October 14, 2014]. 